\title{
O protagonismo do professor Joel Martins na pós-graduação
}

\section{Dermeval Saviani}

Universidade Estadual de Campinas, Faculdade de Educação
O convite para escrever sobre a contribuição do professor Joel Martins ao desenvolvimento da pósgraduação, neste número comemorativo dos quarenta anos de institucionalização dos estudos pós-graduados em nosso país, com certeza foi motivado pelo fato de ter sido eu seu orientando, tendo realizado meu doutorado exatamente no momento em que se desencadeava o processo de regulamentação da pósgraduação; ter convivido com Joel Martins no momento em que se implantavam os programas de estudos pós-graduados na Pontifícia Universidade Católica do São Paulo (PUC-SP); e ter compartilhado com ele essa experiência por duas décadas. Diante dessa circunstância, entendo que se justifica imprimir ao texto um tom de depoimento, mesmo porque, devo confessar, eu teria dificuldades de encontrar outra forma de recuperar a fecunda trajetória acadêmica de Joel Martins. Nessa tarefa recorri às entrevistas por ele concedidas e que foram objeto de distintas publicações. Em especial, apoiei-me no depoimento colhido nos dias 19/9, 15/10 e 13/11/1991, por Sônia Aparecida Ignácio Silva para sua tese de doutoramento, a quem agradeço a gentileza de me ter enviado a transcrição da entrevista que figura como depoimento I do volume II (anexo) da tese (Silva, 1993). Começo, portanto, pelo relato de meu primeiro contato com Joel e prossigo entrelaçando nossas trajetórias desde meu ingresso na carreira universitária até o seu coroamento com o concurso de professor titular na Universidade Estadual de Campinas (UNICAMP), que antecede em apenas dois meses a morte repentina e inesperada daquele que foi, inegavelmente, um dos principais protagonistas da organização e consolidação da pós-graduação brasileira.

\section{Um testemunho}

No final de 1965, mais precisamente em 3 de dezembro, era aprovado no Conselho Federal de Educação (CFE) o parecer n 977/65, de autoria de Newton Sucupira, que tinha por objeto a "definição dos cursos de pós-graduação”. Nesse mesmo final de 1965, eu estava terminando o terceiro ano de meu curso de filosofia na então Faculdade de Filosofia, Ciências e Letras de São Bento, da PUC-SP, e, prosaicamente, por solicitação de um colega do quarto ano, me dirigi 
ao professor Joel Martins para lhe entregar um recado. Ao receber o bilhete, Joel me perguntou à queima-roupa: "Você não gostaria de se especializar em filosofia da educação?”.

Coincidentemente, eu havia recebido, nesse mesmo ano, algumas semanas antes, um convite de José Massafumi Nagamine, secretário da faculdade, para participar de um projeto que envolvia um curso sobre educação internacional a ser organizado no âmbito de um convênio que estava sendo articulado entre a PUCSP e a Universidade Católica de Washington. Desse curso participariam dez alunos, cinco brasileiros e cinco norte-americanos, oriundos de cinco áreas básicas das ciências humanas, constitutivas dos fundamentos da educação. E eu fora convidado para participar desse curso na condição de aluno oriundo da filosofia. Sabendo das relações entre o professor Joel e Nagamine, supus que se tratasse da mesma coisa. Assim, à pergunta: "Você não gostaria de se especializar em filosofia da educação?” respondi: “Como não! Aliás, Nagamine já me falou a respeito, e estou pensando no assunto". A essa minha resposta, o professor Joel retrucou: "É que quem está ministrando a disciplina filosofia da educação no curso de pedagogia é o professor Stanley Krauss, um americano, que em julho retorna aos Estados Unidos, e a cadeira vai ficar vaga. Então, você já poderia começar”.

Foi assim que teve início minha relação com o professor Joel Martins. O projeto do curso de educação internacional acabou não vingando. Quanto ao encaminhamento para a filosofia da educação, Joel me indicou umas leituras, basicamente de Husserl e Merleau-Ponty, além de Dilthey. Em conseqüência desse convite, em 1966, paralelamente ao quarto ano do curso de filosofia, cursei uma opção do quarto ano de pedagogia denominada Questões Especiais de Educação, entre cujas disciplinas figurava Problemas Psicológicos da Educação, ministrada pelo próprio professor Joel. Em meados do primeiro semestre de 1966, em um de nossos encontros, Joel me perguntou como iam as leituras. Respondi: “Devagar, não é, porque o senhor há de convir que, trabalhando em banco pela manhã e cursando, além das quatro disci- plinas do curso de filosofia, mais oito da opção da pedagogia, não me sobra muito tempo para leituras paralelas. Mas às vezes me ocorre como eu daria um curso de filosofia da educação”. Diante dessa minha resposta, Joel imediatamente observou: “Ah! Isso é importante. Ponha sua proposta no papel e me mostre”. Elaborei, então, um programa para a disciplina filosofia da educação e mostrei a ele. Joel analisou e ficou entusiasmado. E nunca mais me perguntou como iam as leituras.

Em julho de 1966, como estava previsto, o professor Stanley Krauss voltou para os Estados Unidos, ficando vaga a cadeira de filosofia da educação. O professor Joel Martins, que integrava o Departamento de Pedagogia na condição de professor de psicologia educacional, assumiu interinamente a cadeira de filosofia da educação e me indicou como monitor, dado que eu me encontrava cursando o quarto ano de filosofia juntamente com a opção Questões Especiais de Educação do quarto ano de pedagogia. Das quatro aulas semanais reservadas à disciplina Joel assumiu duas, em que ele faria orientação de leitura dos alunos, e me destinou as outras duas. Quando lhe perguntei o que deveria fazer naquelas duas horas semanais de aula, ele me respondeu: "Vá desenvolvendo o seu plano". Assim, eu me iniciei no magistério superior como uma espécie de "monitor regente", ministrando as aulas de filosofia da educação para os alunos do terceiro ano de pedagogia, conforme o plano de curso que havia elaborado previamente. No ano seguinte, 1967, na vaga deixada pelo professor Stanley Krauss, foi contratado o professor Casemiro dos Reis Filho. A disciplina filosofia da educação foi desdobrada em duas: fundamentos filosóficos da educação, com duas aulas semanais, no segundo ano do curso de pedagogia, e filosofia da educação, com três aulas semanais, no terceiro ano. Já formado, fui contratado como assistente da cadeira de filosofia da educação, tendo assumido a disciplina fundamentos filosóficos da educação, ficando a disciplina filosofia da educação sob responsabilidade do professor Casemiro dos Reis Filho. Em 1968, Casemiro se deslocou para história 
da educação e eu me tornei responsável pela cadeira de filosofia da educação em sua totalidade.

Portanto, iniciei-me na carreira universitária pelas mãos do professor Joel Martins. E foi também por ele que dei início aos meus estudos pós-graduados. Mas, quem foi Joel Martins?

\section{Uma trajetória incomum}

Joel nasceu em 27 de março de 1920. Segundo seu próprio relato, sua família “era muito bem posta economicamente" e "tinha uma fazenda muito grande em São Carlos do Pinhal” (Silva, 1993, p. 16). Quando menino, foi vivamente tocado pelo contraste entre as condições de vida de sua família e aquelas dos colonos que moravam e trabalhavam na fazenda. Gostava de ir brincar com as crianças da colônia, apesar da “proibição da 'casa-grande', aqui, de nos envolvermos com os meninos, com as crianças da colônia” (idem, ibidem). Sentia-se identificado e, ao mesmo tempo, encontrava-se profundamente sensibilizado com a vida dos colonos:

O sino era tocado às quatro horas da manhã para eles se levantarem, às cinco horas eles saíam para o trabalho, voltavam, almoçavam às onze horas, o sino tocava às onze horas e eles voltavam a trabalhar uma hora depois, meiodia, e às quatro horas o sino tocava e eles voltavam para casa. Então, eu tinha a impressão de um bando de animais tocados através de um sino, que os condicionava ao que tinham que fazer e ao que não tinham que fazer etc. Nesse ínterim, os meus tios e o meu pai percorriam todos os cafezais, que eram vários, não era um só, para saber se eles estavam realmente trabalhando. Então, havia uma desconfiança muito grande do ponto de vista do trabalho do colono. Além disso, quando os colonos chegavam como imigrantes ao porto de Santos, eles já tinham o seu destino determinado... Os fazendeiros iam lá ao porto e traziam os seus colonos. Era a mesma forma de escravidão que eu vim ver depois, quando eu comecei a estudar as migrações escravagistas depois dos holandeses; eu vi, mas isso eu vi com os brancos, com colonos italianos que chegavam, eles faziam isso! (idem, p. 16)
E Joel observava os problemas de saúde que os colonos enfrentavam. Diante disso, tocado pela situação vivenciada, disse para si mesmo: "Vou trabalhar com eles, porque a doença grassava" e "todo o dinheiro que os colonos ganhavam, como salário, era descontado em medicamentos. Eles não recebiam dinheiro algum, porque tudo era descontado com medicamentos” (idem, ibidem). Daí a sua resolução: "Vou ser médico. Eu vou ser médico e vou ficar aqui, nesta fazenda, ou nessa região de fazenda, para atender esse pessoal” (idem, ibidem).

Fica claro, então, porque, logo no início desse depoimento que concedeu para a tese de doutoramento da professora Sônia Aparecida Ignácio Silva, Joel declarou que nunca havia pensado em ser professor e que, "quando era criança - e depois na pré-adolescência - queria ser médico” (idem, p. 1), mas acrescentava: "não médico de estirpe, de grande nome, eu queria ser médico de favela mesmo; médico de grupos desprivilegiados. Porque desde pequeno eu achava que um dos principais problemas deste país era a saúde” (idem, ibidem). E, na seqüência, explicava que, como nunca teve dificuldades na escola, que sempre foi algo simples, muito fácil para ele, não havia sido desafiado a ser professor. Seu desafio era a saúde e, por isso, pensou em ser médico. Além disso, aspirava também a ser músico, alimentando um duplo ideal que aliava a música à medicina: "eram dois ideais, não em conflito, mas dois ideais caminhando paralelamente" (idem, ibidem).

Entretanto, quando cursava o Colégio Batista Brasileiro e já estava terminando o conservatório de piano, ainda na adolescência, sobrevém a morte de seu pai. E sua vida muda inteiramente de direção, pois, nessa nova situação, se sentiu obrigado a seguir uma carreira que lhe desse um retorno financeiro mais imediato. Transferiu-se, então, para o Instituto Estadual de Educação Caetano de Campos, onde concluiu o curso normal:

Então, eu entrei na Escola Normal e fui ser professor! E aí eu disse: bom, se eu tiver que ser professor, eu vou ser aquele médico que eu queria ser, sendo professor... Como 
médico eu estaria trabalhando com pessoas carentes; como professor eu estaria trabalhando com crianças carentes.

(idem, p. 2)

E, de fato, após a conclusão da escola normal, cursada nos anos de 1939 e 1940, Joel trabalhou com crianças carentes, lecionando em escola da zona rural durante seis meses, após ter já se iniciado como professor substituto enquanto fazia o curso normal, quando, entusiasmado, concluiu: “É por aí mesmo, é por aí que eu devo prosseguir, é por aí que eu devo continuar" (idem, ibidem). E os problemas enfrentados no campo educacional o provocaram a retomar os estudos, ingressando na Faculdade de Filosofia, Ciências e Letras da Universidade de São Paulo (USP), onde, no início da década de 1940, cursou concomitantemente filosofia e pedagogia:

Em 42 eu entrei na Faculdade de Filosofia. O meu interesse não era estudar como ensinar, aprendizagem, essas coisas que estavam tão desgastadas para mim. O que me interessava realmente era ir além, um pouco além disso: um pensar filosófico da aprendizagem, [um pensar] filosófico do ensino, um pensar filosófico da educação. Então, eu tive um curso de Filosofia conjugado com o curso de Pedagogia. (idem, p. 4)

Tendo concluído brilhantemente o curso superior, foi chamado a ocupar cargos importantes como a direção do Instituto de Educação de Espírito Santo do Pinhal, no interior do Estado de São Paulo, e do Instituto de Educação Padre Anchieta, no bairro do Brás, na capital paulista. Aprovado em concurso público para o exercício do magistério, foi designado como professor do Instituto de Educação Castelo Branco, de Limeira, mas, nesse mesmo momento, recebe uma bolsa de estudos para fazer o mestrado nos Estados Unidos, onde permaneceu entre 1949 e 1950. Retorna ao Brasil em meados de 1950 e é chamado pela professora Noemy Rudolfer para ser auxiliar extranumerário da cadeira de psicologia, na USP, onde, entre 1951 e 1953, faz o doutorado em psicologia da educação. Sua pesquisa deu-se no campo da psicologia experimental, de orientação behaviorista, e o resultado o deixou muito insatisfeito. Em conseqüência, Joel resolveu retornar aos Estados Unidos, na Universidade de Michigan, onde esperava encontrar solução para os problemas com os quais se defrontou em sua pesquisa de doutorado, cujo objeto girava em torno da escolha de alternativas realizada por ratos observados em laboratório.

Em seus estudos de pós-doutorado na Universidade de Michigan, em Ann Arbor, realizados entre 1953 e 1954, Joel deparou-se com comportamentos não previstos dos ratos no labirinto, o que, segundo o seu relato, desorganizava completamente o seu projeto experimental (idem, p. 9). E, no mesmo momento em que se deparava com esse problema, "um grande professor americano, Edward Tolman, da Universidade da Califórnia, publicou um trabalho: $O$ comportamento do rato num ponto de escolha" (idem, ibidem), que coincidia exatamente com o seu problema. Tomou um avião e foi expor o seu experimento ao professor Tolman, que, após ouvir seu relato, o fitou fixamente e disse: "Por que o senhor não se coloca no lugar do rato? O que é que o senhor faria se o senhor fosse rato e estivesse lá naquele labirinto?”. Joel conta que, de imediato, ficou surpreso com aquela reação, e até mesmo um tanto revoltado com a idéia de se colocar no lugar do rato. Mas, ao retornar para casa, ficou pensando que, de fato, "ele tinha razão, porque eu tinha pensado no rato como um simples objeto, como um simples animal”, como se "variáveis as mais estranhas não estivessem influenciando o comportamento daquele animal” (idem, p. 10). E o professor Joel encerra seu comentário nos seguintes termos:

Acabei o trabalho e terminei essa fase da minha vida acadêmica. Quando eu vim-me embora é que eu comecei a pensar na multiplicidade da vida do homem e que os comportamentos não podem ser simples estímulos-respostas, não podem ser simples linearidade, como apresentavam os psicólogos behavioristas e comportamentistas, mas que havia uma polarização de possibilidades e de influências orientando, determinando o comportamento. (idem, p. 10) 
Certamente aí está o gérmen de sua aproximação à fenomenologia existencial, que o conduziu à leitura de autores "como Kierkegaard, Husserl, Heidegger, Merleau-Ponty, Paul Ricoeur, sempre preocupado com a educação e com a psicologia da educação" (Bicudo \& Espósito, 2002, p. 178). Essa tendência será sua principal matriz filosófica, cujo estudo ele fará sistematicamente, seja mediante a organização do Centro de Estudos Fenomenológicos de São Paulo (idem, p. 190), seja pela criação, em 27 de março de 1989, da Sociedade de Estudos e Pesquisas Qualitativos (idem, p. 192), que buscava desenvolver pesquisas segundo a abordagem qualitativa-fenomenológica.

Joel descreve essa sua trajetória com uma pitada de humor ao lançar mão da expressão "dos ratos à fenomenologia”. Mas insiste que, embora aparentemente simples, essa passagem não foi repentina, mas muito sofrida, tendo origem em sua viagem à Europa, onde teve contato com Merleau-Ponty, freqüentando "um curso belíssimo” sobre fenomenologia da percepção. Do estudo de Merleau-Ponty ele voltou a Husserl, que “era o ponto de partida”, e a seu antecessor, Brentano. Daí, seguiu para Heidegger e Paul Ricoeur (Silva, 1993, p. 30). E completa seu relato:

Hoje eu faço uma fenomenologia... eu não diria minha, mas pelo menos com recurso que a fenomenologia me dá para fazer pesquisa. Eu não estou interessado nas grandes reflexões fenomenológicas, eu não estou interessado nas análises dos trabalhos de Merleau-Ponty, que são trabalhos muito importantes, muito sérios... Mas eu estou interessado é na pesquisa, como é que se vai fazer pesquisa humana, usando o recurso da fenomenologia. (idem, ibidem).

E à pergunta sobre se ele vê uma intersecção entre fenomenologia e materialismo histórico, responde:

Pode ser feita. Eu vejo isso, Merleau-Ponty fez isso nas “Aventuras da dialética”. [...] Acho que Sartre a mesma coisa, faz essa intersecção sim. Mas é uma intersecção muito sutil, ela não é, na realidade, uma derivação do materialismo histórico ou da fenomenologia, quer dizer, é... é mesmo uma intersecção, um cruzamento. [...] Porque uma intersecção entre dois discursos forma uma região vazia e que precisa ser preenchida. Se for assim, é melhor ainda, quer dizer, a intersecção do marxismo com a fenomenologia gera uma região que precisa ser trabalhada... (idem, p. 31)

Concluídos seus estudos de pós-doutorado em Michigan, Joel retornou ao Brasil, em 1955, e foi trabalhar, "a convite de Anísio Teixeira, no Centro Regional de Pesquisas Educacionais, cujo diretor era Fernando de Azevedo" (Buffa \& Nosella, 2001, p. 20). Aliás, conforme Bicudo e Espósito (2002, p. 176), Joel integrou "o grupo que criou os Centros Regionais de Pesquisas Educacionais, tendo sido diretor de Pesquisas do Centro de São Paulo”. E, no final da década de 1950 e início dos anos de 1960, atuou como especialista na Organização das Nações Unidas para a Educação, a Ciência e a Cultura (UNESCO) e na Organização dos Estados Americanos (OEA). Conforme seu depoimento, o convite para a UNESCO decorreu de um projeto que havia elaborado, algum tempo antes, "sobre a preparação de pesquisadores para a América Latina” (Silva, 1993, p. 10). Em 1961 voltou ao Brasil, indo trabalhar como professor de psicologia na Faculdade Sedes Sapientiae, em São Paulo. Em 1963, atendendo a convite do monsenhor Enzo de Campos Gusso, então diretor da Faculdade de Filosofia, Ciências e Letras de São Bento, iniciou sua carreira docente na PUC-SP, também como professor de psicologia. Mas o convite do padre Enzo explicitava que, além de dar aulas, Joel deveria ajudar "na organização e montagem da faculdade etc." (idem, p. 11). De fato, padre Enzo havia assumido a direção da Faculdade de Filosofia, Ciências e Letras de São Bento, da PUC-SP, “no final de 1960, com a decisão pessoal de nela promover uma profunda reforma com vistas à instalação de um processo que, a médio prazo, deveria atingir toda a Universidade” (Nagamine, 1997, p. 57).

Eis como o professor Joel Martins veio a se envolver inteiramente com o processo de reforma da PUC-SP: participou da elaboração do projeto de reforma e da liderança de sua implantação, de modo especial no que se refere à criação do setor de pós- 
graduação; e ocupou postos na alta administração da instituição, como os cargos de presidente da Comissão Central de Pós-Graduação, vice-reitor acadêmico e, finalmente, reitor, cujo mandato se iniciou em novembro de 1992. E foi na condição de reitor da PUC-SP que a morte o colheu subitamente, na madrugada do dia 2 de maio de 1993. Pouco antes, em fevereiro de 1993, Joel participou da banca julgadora de meu concurso de professor titular na UNICAMP, o que me deixou muito feliz, pois aquele que me havia iniciado na carreira universitária, ali estava presente no momento em que eu atingia o topo dessa mesma carreira. Naquela oportunidade ele me argüiu com toda a vivacidade que lhe era característica. Encontravase em plena forma, cheio de planos no início de sua gestão como reitor da PUC-SP, com destaque para o projeto “A PUC do Futuro” (Bicudo \& Espósito, 2002, p. 193-200). Jamais poderíamos suspeitar que, dentro de pouco mais de dois meses, ele nos deixaria para sempre.

\section{A pós-graduação}

Retornemos a 3 de dezembro de 1965. O conselheiro Newton Sucupira, no preâmbulo ao parecer CFE $n^{\circ} 977 / 65$, informa que a iniciativa de solicitar a manifestação do CFE partiu de aviso ministerial que pedia um pronunciamento do conselho no sentido de definir e, se possível, regulamentar os cursos de pósgraduação previstos na letra b do artigo 69 da Lei de Diretrizes e Bases da Educação Nacional (LDB) de 1961. Tendo em vista que nesse artigo da LDB a menção aos cursos de especialização e aperfeiçoamento se encontrava na alínea c, Sucupira considerou que a definição pedida pelo ministro se circunscrevia à pós-graduação stricto sensu. E foi nesse âmbito que se moveu a conceituação de pós-graduação apresentada em seu parecer.

Quanto ao outro aspecto contido no aviso ministerial referente à regulamentação, Newton Sucupira observa que isso não seria possível porque a mesma LDB limitava, no dispositivo seguinte (artigo 70), a competência do CFE para fixar o currículo e a dura- ção dos cursos àqueles cujos diplomas conferiam prerrogativas para o exercício de profissão liberal. Ora, lembra o relator, apenas um curso de pós-graduação satisfazia essa condição de conferir privilégio profissional: o curso de orientação educativa. Assim, não cabia ao conselho regulamentar os cursos de pósgraduação de modo geral (Brasil, 1965, p. 69).

Dessa forma, atendo-se às determinações legais, Newton Sucupira cuidou, em seu parecer, da conceituação da pós-graduação, não tratando de sua regulamentação, o que veio a ocorrer apenas posteriormente.

Após tratar da "origem histórica da pós-graduação” e da "necessidade da pós-graduação”, Newton Sucupira deu uma conceituação geral em que distingue a pós-graduação sensu stricto e sensu lato, concluindo com o seguinte conceito de pós-graduação stricto sensu: "o ciclo de cursos regulares em seguimento à graduação, sistematicamente organizados, visando desenvolver e aprofundar a formação adquirida no âmbito da graduação e conduzindo à obtenção de grau acadêmico" (idem, p. 74).

Para explicitar o referido conceito, o relator, por entender que "a pós-graduação - o nome e o sistema tem sua origem próxima na própria estrutura da universidade norte-americana” (idem, p. 69), apóia-se na experiência dos Estados Unidos. E, após considerar os aspectos legais estipulados na LDB e no Estatuto do Magistério, encerra o parecer com o enunciado de dezesseis conclusões, à guisa de diretrizes para a implantação dos cursos de pós-graduação.

A regulamentação, propriamente dita, será objeto de um novo parecer, também de autoria de Newton Sucupira, aprovado pela Câmara de Ensino Superior (CES) do CFE em 11 de fevereiro de 1969. Isso se tornou possível porque os dispositivos da LDB relativos ao ensino superior foram modificados pela lei $\mathrm{n}^{\circ}$ 5.540, promulgada em 28 de novembro de 1968. Essa lei estabeleceu que "o CFE conceituará os cursos de pós-graduação e baixará normas gerais para sua organização, dependendo sua validade, no território nacional, de os estudos neles realizados terem os cursos respectivos credenciados por aquele órgão” (art. 24). Está fixada aí a competência do conselho para 
regulamentar a organização da pós-graduação, surgindo também a figura do credenciamento como prerrogativa do mesmo conselho.

Apoiado nessa nova norma legal, o mesmo conselheiro Newton Sucupira, evidentemente tomando por base as dezesseis conclusões que fecharam o parecer CFE $n^{\circ} 977 / 65$, elaborou o parecer $n^{\circ} 77 / 69$, que fixou os procedimentos, requisitos e condições para o credenciamento dos cursos. A partir daí desencadeou-se o processo de instalação da pós-graduação no Brasil, começando pelo mestrado e se completando com o doutorado.

\section{Joel Martins e a pós-graduação}

Tendo eu me iniciado na carreira universitária, ainda antes de concluir meu curso de graduação, pelas mãos do professor Joel Martins, assim que me formei e fui indicado para assistente da cadeira de filosofia da educação, Joel redigiu uma carta endereçada ao professor Roque Spencer Maciel de Barros, catedrático de filosofia da educação da USP, encaminhando-me para fazer mestrado. É que havia sido divulgado um prospecto que previa a oferta de um curso de mestrado em filosofia da educação na Faculdade de Filosofia, Ciências e Letras da USP. Dirigi-me àquela instituição e fui informado, na secretaria da faculdade, que o prospecto se referia a um projeto de criação do curso, mas as inscrições ainda não estavam abertas e nem havia previsão da época em que o curso teria início. Retornei à PUC-SP e comuniquei essa informação ao professor Joel, que me aconselhou: "Inscreva-se, então, para o doutorado aqui mesmo na PUC”.

Esse encaminhamento era possível porque, à semelhança da sistemática vigente nas universidades européias, os estatutos e regimentos das universidades brasileiras tenderam a instituir o grau de doutor obtido mediante a elaboração e defesa pública de uma tese perante uma banca examinadora constituída pela administração superior da universidade, sob a presidência do orientador. Para tanto, o professor que preenchia os requisitos definidos no regimento deveria formalizar sua inscrição, sendo indicado um orientador. A partir daí ele iria desenvolvendo sua pesquisa e, concluída a tese, procedia-se à constituição da comissão julgadora e marcava-se a data da cerimônia de defesa pública da tese, que ocorria em moldes semelhantes às atuais defesas de tese de doutorado.

À vista das circunstâncias mencionadas, seguindo o conselho do professor Joel, efetuei minha inscrição em fevereiro de 1968 para realizar meu doutoramento na área de ciências humanas, com especificação em filosofia da educação. Quanto à definição do orientador, Joel, cautelosamente, me perguntou se eu não preferia que fosse indicado alguém do Departamento de Filosofia. Respondi-lhe que, tendo sido formado em filosofia, eu me sentia razoavelmente seguro nessa área. Assim, ao me definir pelo campo da filosofia da educação, eu precisava trabalhar mais sistematicamente a questão educacional, me familiarizar mais com a problemática pedagógica. Em conseqüência, eu preferia ter interlocução sistemática com alguém da área de educação, com experiência de pesquisa consolidada nessa área. Em suma: eu gostaria que o próprio professor Joel fosse meu orientador. Ao ouvir essa minha manifestação, Joel esboçou um ar de satisfação e assumiu formalmente o processo de orientação. Na verdade, essa era a conseqüência natural de um processo que se iniciara com aquele convite formulado no final de 1965. Penso que ele fizera aquela consulta em respeito à minha liberdade de decidir sobre a escolha do orientador, e também, provavelmente para se certificar de que, de fato, eu tinha a intenção de desenvolver meu trabalho de pesquisa com o seu acompanhamento.

Estávamos, então, no início de 1968. Naquele momento Joel Martins já despontava como o principal articulador e incentivador dos estudos pós-graduados e do desenvolvimento de pesquisas na PUCSP, pois desde o ano anterior ele vinha procurando enfrentar "a necessidade urgente de preparar os escalões da universidade” (Silva, 1993, p. 12). Para isso ele articulou junto à reitoria a criação de um regime de doutoramento, que depois veio a se chamar de "regime antigo", para viabilizar a obtenção do douto- 
rado aos professores da universidade. Isso porque, segundo ele, havia "muita gente matura, dentro da instituição, para fazer um doutoramento. Gente com experiência didática, com experiência de pesquisa, com publicação etc.” (idem, ibidem). Em conseqüência, grande número de docentes da instituição se inscreveu para obter o doutorado com sua orientação.

No entanto, essas inscrições eram individuais, e nem todos, efetivamente, se dedicavam sistematicamente ao trabalho de pesquisa fazendo progressos visíveis na produção da tese de doutoramento. De minha parte, apesar de sobrecarregado de aulas, pois, além da universidade, era também professor em escola de nível médio da rede pública estadual, me organizei de modo a poder dedicar um mínimo de horas semanais à elaboração da tese. Assim é que, quando fiz a revisão da literatura da tese, em 1970, eu ministrava 17 aulas semanais na universidade e 26 no colégio estadual. Estava em sala de aula todas as manhãs, todas as noites e, às sextas-feiras, também às tardes. Obrigueime, então, a dedicar pelo menos dezesseis horas semanais à tese (de segunda a quinta-feira à tarde), comprometendo-me a repor, num fim de semana ou feriado, caso algum dia isso não fosse cumprido em função, por exemplo, de alguma reunião de professores convocada para o período da tarde. Transferi, também, para os fins de semana as preparações de aulas e a correção de trabalhos dos alunos. Cumpri à risca esse programa e, na primeira semana de setembro de 1971, entreguei ao orientador o texto da tese concluída, que, após sua apreciação, foi submetida à defesa pública no dia 18 de novembro desse mesmo ano. Fui um dos primeiros, senão o primeiro dentre os orientandos do professor Joel Martins a obter o título.

Pela sua maneira franca de ser e de agir, pela sua autenticidade e honestidade de propósitos, o professor Joel Martins "não se ocultava sob máscaras ou papéis predefinidos”, característica que o tornava "amado e odiado, fascinante e inoportuno" (Bicudo \& Espósito, 2002, p. 178), sendo corrente o sentimento de que era impossível relacionar-se com ele sem atritos, como ilustra esse depoimento de Sérgio Luna: "Aliás, a única relação que nós tivemos foram algumas brigas por cartas. Que também, se relacionar com o Joel sem brigar, é absolutamente impossível... Não tem como” (idem, ibidem). Sendo essa a percepção generalizada, concluo que sou uma espécie de exceção que confirma a regra, pois, em todo o meu convívio com o professor Joel, que durou mais de vinte anos, nunca tive com ele qualquer tipo de desentendimento.

Paralelamente ao encaminhamento de realização do doutorado pelo chamado "sistema antigo", desenvolviam-se, com a liderança do professor Joel, as iniciativas de se organizar a pós-graduação na PUC-SP de acordo com a nova sistemática decorrente do parecer $\mathrm{n}^{0} 77 / 69$ do CFE, que, segundo o professor Joel, era "uma cópia papel-carbono do que acontecia nos Estados Unidos” (Silva, 1993, p. 13). De fato, ao elaborar o parecer CFE $n^{\circ}$ 977/65, o conselheiro Newton Sucupira baseou-se no modelo norte-americano para conceituar a pós-graduação a ser implantada no Brasil.

Aprovado o parecer CFE $\mathrm{n}^{\circ}$ 77/69 em fevereiro de 1969, nesse mesmo ano tiveram início os programas de estudos pós-graduados: em psicologia educacional, coordenado por Joel; em sociologia, coordenado pelo professor José Pastore; em teoria literária, que depois veio a se chamar comunicação e semiótica, coordenado pela professora Lucrecia D’Alessio Ferrara; e em lingüística aplicada ao ensino de línguas, coordenado pela professora Maria Antonieta Alba Celani (Nagamine, 1997, p. 127). Quanto ao programa de sociologia, logo foi interrompido porque o professor Pastore deixou a PUC, transferindo-se para a USP. Mas em 1971 foi instalado o Programa de Estudos PósGraduados em Ciências Sociais, com a coordenação da professora Carmen Junqueira. Iniciava-se, assim, o Setor de Pós-Graduação da PUC-SP, instituído pelo professor Joel Martins, que veio a se tornar um dos centros mais importantes de formação pós-graduada no país. Mas, para chegar a esse resultado, foi necessário enfrentar e superar muitas dificuldades.

Com efeito, as exigências para implantação de pós-graduação, definidas pelo parecer $n^{0} 77 / 69$, eram de tal ordem que, segundo Joel, "simplesmente 
delimitava[m] a possibilidade de pós-graduação a grandes universidades, a universidades que eram pólo" (Silva, 1993, p. 13). E a PUC-SP “era uma Universidade ainda muito pequena, onde as relações interpessoais e a tradição catedrática da organização acadêmica prevaleciam” (Nagamine, 1997, p. 126), situação agravada pelo espaço físico restrito:

O único espaço ainda não ocupado era o porão do prédio... Literalmente, tratava-se de porão com várias repartições ligadas por um corredor interno, sem comunicação externa, senão por pequenas janelas gradeadas. E foi aí que o professor Joel, em 1969, instalou as coordenações dos primeiros Programas de Estudos Pós-Graduados da PUCSP. (idem, p. 127)

Para isso foi preciso muita determinação e persistência. Joel relata que ele e José Nagamine se dirigiram ao professor Bandeira de Mello, então reitor da universidade, dizendo: "Nós vamos fazer aqui, vamos fazer aqui na PUC, não obstante essa recomendação, ou restrição do CFE. Vamos ver o que acontece” (Silva, 1993, p. 13). Diante dessa veemência, o reitor ponderou: "Olhe, é uma temeridade, vocês não estão obedecendo leis...”, ao que Joel retrucou: “Mas a gente está tentando a vida acadêmica dentro de uma instituição que é livre, que é particular, que é livre! E que pode fazer o que achar bom fazer!” (idem, ibidem). Diante disso, foi autorizada a montagem do projeto de pós-graduação.

Com a liderança de Joel Martins, a pós-graduação da PUC-SP tornou-se uma referência nacional, que rapidamente atraiu a atenção do governo federal:

A [Coordenação de Aperfeiçoamento de Pessoal de Nível Superior] CAPES tinha um respeito muito grande pelo programa de pós-graduação daqui, porque era o único no Brasil que não pertencia aos Departamentos, de acordo com a Lei 5.540, mas era um setor à parte e, à maneira das universidades estrangeiras, em Londres, Estados Unidos, França, a pós-graduação tem a sua biblioteca, tem a sua própria área de pesquisa, tem os seus próprios cursos, professores etc. (Silva, 1993, p. 14)
Em entrevista concedida a Ester Buffa e Paolo Nosella, em 21 de novembro de 1985, Joel retoma, de outra maneira, o mesmo tema:

Eu não precisava da confiança do governo federal. Queria a confiança da minha Universidade, do meu reitor e do pessoal com quem trabalhava. Gradualmente, a relação foi melhorando, porque o curso de pós-graduação da PUC era um modelo; era o único que estava organizado, que tinha antecedentes. A CAPES veio aqui para saber como é que a gente conseguiu, numa escola particular, com poucos recursos, montar a pós-graduação. (Buffa \& Nosella, 2001, p. 151)

De fato, a pós-graduação na PUC-SP foi organizada como um setor autônomo, independente dos centros, faculdades e departamentos que configuravam a estrutura da universidade nos termos da reforma decorrente da lei $n^{\circ} 5.540$, promulgada em 28 de novembro de 1968. Diferentemente dessa estrutura, o parecer CFE $n^{\circ}$ 977/65, que conceituou a pós-graduação, recomendava na conclusão de número 13: "Nas Universidades a pós-graduação de pesquisa ou acadêmica deve ser objeto de coordenação central, abrangendo toda área das ciências e das letras, inclusive das que fazem parte do ciclo básico das faculdades profissionais” (Brasil, 1965, p. 86). Igualmente, o parecer $\mathrm{n}^{0} 77 / 69$, que regulamentou a implantação da pós-graduação, estabeleceu no inciso XII do artigo 13: "Nas Universidades a pós-graduação deve ser objeto de coordenação central” (Brasil, 1969, p. 131).

Quanto ao "regime antigo", foi criado um "programa especial” de doutorado para atender aos professores inscritos anteriormente à regulamentação da pós-graduação pelo parecer n 77/69 “e tendo em vista, também, a própria viabilização desses programas de mestrado para cujo funcionamento exigia-se professor com, no mínimo, titulação de doutor” (Nagamine, 1997, p. 128). Esse programa especial, regulamentado pela portaria $n^{\circ} 31 / 71$, do reitor Bandeira de Mello, estabeleceu os seguintes requisitos:

a) elaboração de um projeto orientado por um professor doutor; 
b) realização de cursos relacionados diretamente com o objetivo da pesquisa (mínimo de três);

c) redação e defesa de tese original no campo da especialidade do candidato e do orientador. (idem, p. 128-129)

Foi dessa maneira que se fez a transição entre o “antigo regime” e o "novo regime” dos estudos pósgraduados na PUC-SP. No meu caso particular, tendo feito minha inscrição para realizar o doutorado em fevereiro de 1968, portanto, antes da regulamentação da pós-graduação, estava desenvolvendo meu projeto de tese de doutoramento. E, para atender ao segundo requisito definido no programa especial de doutorado, cursei a disciplina lógica do conhecimento científico, ministrada pelo professor doutor Leônidas Hegenberg, o "Seminário sobre Martin Buber" e o "Seminário sobre Emmanuel Mounier”, ambos coordenados pelo professor doutor Newton Aquiles Von Zuben. Assim, ao concluir a redação da tese denominada $O$ conceito de sistema na lei de diretrizes e bases da educação nacional, estavam preenchidos os três requisitos do programa especial, habilitando-me a submeter a tese à defesa pública com vistas à obtenção do título de doutor em ciências humanas: filosofia da educação.

Da PUC-SP a influência do professor Joel Martins na pós-graduação brasileira se irradiou para outras instituições, não apenas indiretamente, por meio dos quadros formados na PUC-SP e que passaram a atuar em outras universidades, mas também diretamente. Foi esse o caso do Instituto Educacional Piracicabano, hoje Universidade Metodista de Piracicaba (UNIMEP), cuja pós-graduação nasceu de entendimentos com Joel, que para lá encaminhou a equipe que estava dando início ao Programa de Estudos Pós-Graduados em Filosofia da Educação da PUC-SP. Também foi esse o caso da UNICAMP, cujo programa de pós-graduação em educação foi criado com a decisiva colaboração de Joel Martins. Em reconhecimento a essa contribuição ele recebeu, em 1992, o título de professor emérito da UNICAMP, e a biblioteca da Faculdade de Educação recebeu, em 1993, a denominação de "Biblioteca Professor Joel Martins”.

\section{Qualificação docente}

As realizações do professor Joel na pós-graduação se inserem no âmbito de uma preocupação maior, traduzida "na idéia de um programa de capacitação docente como condição indispensável para a consistência do desejado salto de qualidade no ensino" (Nagamine, 1997, p. 126). É nesse sentido que se articulam suas ações como diretor do Instituto de Educação do Espírito Santo do Pinhal, quando recuperou a dignidade da escola e introduziu cursos de aperfeiçoamento para os docentes mediante convite a professores mais experimentados; como diretor do Instituto de Educação Padre Anchieta, no bairro do Brás, em São Paulo, uma escola feminina com mais de 2.000 moças, restaurando a moralidade e resgatando a qualidade educativa da instituição; igualmente se insere naquela preocupação maior seu projeto de preparação de pesquisadores para a América Latina, assim como o exercício do cargo de diretor de pesquisas do Centro Regional de Pesquisas Educacionais "Prof. Queiroz Filho”, braço paulista do Centro Brasileiro de Pesquisas Educacionais; e sua atuação nos ginásios vocacionais do estado de São Paulo e na escola experimental da Lapa. Na PUC-SP, além de liderar a organização da pós-graduação e presidir a Comissão Geral do Setor de Pós-Graduação durante vários anos, Joel constituiu um grupo de apoio didático-pedagógico visando promover uma reflexão permanente sobre o caráter educativo da prática docente de todas as carreiras universitárias. Para dar início às atividades do grupo, elaborou um texto que, sendo classificado como "Documento 1”, estava indicando que a idéia era desencadear um processo em que vários textos fossem produzidos para alimentar a reflexão e o debate sobre o significado fundamental do trabalho educativo na universidade. Ao ensejo deste artigo solicitado pela Associação Nacional de Pós-Graduação e Pesquisa em Educação (ANPEd), evidenciando o papel desempenhado por Joel Martins no desenvolvimento da pós-graduação no Brasil, considero oportuno revelar o teor integral do primeiro documento redigido por ele para dar início aos trabalhos do Grupo de Apoio Didático-Pedagógico, se- 
guido dos comentários que redigi, respondendo ao apelo nele contido. Trata-se de documentos, ao que eu saiba, inéditos, nos quais não foi registrada a data de sua redação. Transcrevo, a seguir, os dois documentos, procurando, na medida possível, preservar o formato original.

\section{Anexo}

\section{Documento 1 \\ PROPOSTA PARA REFLEXÃO \\ Joel Martins \\ REFLEXÕES SOBRE EDUCAÇÃO}

1. Dificuldade de formular uma proposição simples e suficientemente abrangente que pudesse dizer o que é a educação.

1.1. colocamo-nos numa situação difícil tanto do ponto de vista filosófico como do ponto de vista psicológico. Determinar fins e meios da educação é uma forma simplista de olhar o problema.

2. Talvez o melhor ponto de partida devesse ser mesmo a formulação de uma pergunta pedagógica por todos aqueles que se defrontam com a educação.

2.1. quem deve propor essa pergunta pedagógica?

2.2. aqui já se propõe inicialmente um conceito de pesquisa, uma vez que toda pergunta é o gerador de uma pesquisa.

2.3. no que se refere à pergunta pedagógica, trata-se de responder a uma pergunta sobre o educador (quem educa) e sobre o educando (o aluno ou o ser do aluno).

2.4. a proposição da pergunta pedagógica refere-se a um comportamento de um Ser (professor) que questiona e tem um característico de ser que lhe é próprio.

2.4.1. nesse particular pode tomar ou assumir a forma de uma conversa interrogativa;

2.4.2. pode tomar a forma de uma explicitação de algo que se realiza.

3. Ao formular a pergunta pedagógica tem-se em vista a possibilidade de se conduzir uma pesquisa.

3.1. o sentido da educação deve ser possível. Essa questão exige algumas qualificações.

3.1.1. em primeiro lugar ter-se-á que dizer o que a educação é, sem que se possa qualificar o que esse “é” significa.

3.1.2. a questão pedagógica deve ser clara e transparente; isso quer dizer que a pergunta pedagógica é visível com características próprias e distintas.
3.1.3. o inquérito gerado pela pergunta pedagógica deve significar uma busca cognitiva.

3.1.3.1. cognição é um ato consciente que tem um objeto primeiro e um objeto segundo.

3.1.3.1.1. a consciência mais simples teria como objeto na pergunta pedagógica a existência de um professor e de um aluno numa instituição.

3.1.3.1.2. como objeto segundo, a consciência apresenta-se como representação, como conhecimento e como sentimento.

4. No caso da pergunta pedagógica, ao propor a pergunta o inquiridor deverá ter já à sua disposição um significado para educação. Esse significado pode estar apresentado de formas ainda obscuras.

4.1. o inquiridor pedagógico se vê como um "bom” especialista;

4.2. o inquiridor pedagógico se vê como um "bom” profissional;

4.3. o inquiridor pedagógico se vê como um "bom” conhecedor.

A atividade de pesquisa será, então, compreender o que é educação.

A primeira informação que o inquiridor possui quando inicia a investigar a pergunta pedagógica é um significado da relação professor aluno na instituição.

Ainda que essa relação esteja obscurecida pelos conceitos anteriores de ensino, aprendizagem, avaliação etc. Mas já estamos diante de um fato.

Esse “é” educação pode, porém, estar indefinido, perder-se ou infiltrar-se de teorias tradicionais ou metodológicas.

Na pergunta pedagógica que deve iniciar o inquérito sobre educação o que se busca é aquilo que determina a educação como tal, aquilo que deverá tornar essa entidade educação compreendida.

5. Na pergunta pedagógica que aponta para o ser da educação é preciso separar bem claramente as entidades como entidades 
e não pensar que a educação está escondida nessas entidades. Dessa forma a educação deve ser demonstrada na sua própria essência, diferente das formas pelas quais as entidades são descobertas.

6. A educação precisa estar visível para o pesquisador de uma maneira própria e adequada, contrastando essencialmente com os conceitos por meio dos quais as entidades adquirem significados.

7. Se a pergunta pedagógica deve ser explicitamente formulada de maneira que se torne transparente a si mesma, deve exigir uma explicação de como a educação deve ser vista, de como o seu significado pode ser compreendido conceptualmente. A escolha correta para a busca da resposta à pergunta pedagógica será construir o caminho genuíno de acesso a ela.

8. Sempre que olhamos para alguma coisa procuramos compreendê-la, conceituá-la e nos aproximar dela - são os constituintes do inquérito sobre a educação que estamos descobrindo.

9. Ao propor a pergunta pedagógica que aponte para a educação torna-se necessário:

9.1. primeiro, um inquiridor para o qual a educação é transparente. Esse inquiridor é o ser ou entidade que promove a educação.

9.2. o pressuposto de que toda a entidade é e, portanto, possui uma essência ou uma configuração que lhe é própria dá origem a toda a investigação que resulta numa cognição e conseqüentemente num conhecimento.

9.2.1. o perigo na proposição da pergunta pedagógica cujo inquérito deve apontar para o ser da educação é partir-se de pressupostos sem que se saiba que estão buscando os seres das entidades que estudam.

Esse documento transcrito foi proposto para os participantes do Grupo de Apoio Didático-Pedagógico, evidentemente com o intuito de provocar uma resposta reflexiva que desse seqüência ao inquérito instaurado. Respondendo a esse apelo, redigi algumas notas, respeitando a numeração dos itens do documento inicial, dando origem ao Documento 2. A seguir, transcrevo o teor desse documento.

\section{Documento 2}

COMENTÁRIOS SOBRE A PROPOSTA DO DOCUMENTO 1

\section{Dermeval Saviani}

NOTAS À MARGEM DAS "REFLEXÕES SOBRE EDUCAÇÃO", DO PROFESSOR JOEL

1. A dificuldade é posta, aqui, no nível de uma apreensão imediata, sendo desdobrada e assumindo contornos mais nítidos na exposição dos itens seguintes.

2. O que se deve entender por pergunta pedagógica? Considerando-se que esse Grupo de Apoio Didático-Pedagógico foi constituído para atender a uma necessidade determinada (implementar o caráter educativo das atividades do professor universitário da PUC-SP), a pergunta pedagógica aponta para a necessidade de se desvelar o ser da educação (o “o quê” pedagógico) que torna educativas as diferentes especialidades (científicas, literárias, profissionais etc.) que são objetos de cursos ministrados pela PUC-SP. A pergunta pedagógica, por conseguinte, propõe a educação como um problema, isto é, como algo que se desconhece e que se necessita conhecer. O problema, contudo, apresenta um lado subjetivo e um lado objetivo, intimamente conexionados numa unidade dialética. Com efei- to, a necessidade, que é a essência do problema, só pode existir se ascender ao plano consciente, isto é, se for sentida pelo homem como tal (aspecto subjetivo); há, porém, circunstâncias concretas que objetivam a necessidade sentida, tornando possível, de um lado, avaliar o seu caráter real ou suposto (fictício) e, de outro, prover aos meios de satisfazê-la. Diríamos, pois, que o problema implica tanto a conscientização de uma situação de necessidade (aspecto subjetivo) como uma situação conscientizadora da necessidade (aspecto objetivo). É a partir daí que se torna possível distinguir o problema do pseudoproblema.

2.1. Portanto, devem propor a pergunta pedagógica aqueles (dentre os professores da PUC-SP) que sentem a necessidade de desvelar o ser da educação, isto é, aqueles para os quais a educação se manifesta como problema.

2.2. A pesquisa desencadeada pela pergunta pedagógica poderá, então, se constituir no processo de desvelamento dos aspectos subjetivo e objetivo do problema-educação.

2.3. A pergunta pedagógica incide fundamentalmente sobre o educador (quem educa) e sobre o educando (o aluno ou o ser do aluno). Cabe notar, porém, que educador e educando não entram em relação entre si como indiví- 
duos que se defrontam diretamente, mas mediados por um conjunto complexo de elementos.

N.B. O homem não se identifica com o indivíduo. $\mathrm{Na}$ caracterização do homem cumpre levar em conta: a) a natureza; b) as relações sociais; c) o indivíduo. O “ser-educador” não é um "ser-indivíduo”, mas já é, ele próprio, um "ser-relações sociais”. O mesmo se diga do “ser-educando”.

2.4. A característica própria do ser (professor) a cujo comportamento a pergunta pedagógica se refere diz respeito ao “ser-relações sociais”. Assim sendo, os itens 2.4.1 e 2.4.2 podem ser considerados de duas formas: distintamente e conjuntamente.

Distintamente:

2.4.1. A pergunta pedagógica assumindo a forma de uma conversa interrogativa poderá consistir, ela mesma, no processo de percepção (tomada de consciência) do problema-educação (conscientização de uma situação de necessidade);

2.4.2. A pergunta pedagógica, enquanto explicitação de algo que se realiza, consistirá na caracterização do aspecto objetivo do problema-educação (situação conscientizadora da necessidade).

Conjuntamente:

2.4.1. e 2.4.2. A conversa interrogativa, desenrolandose na forma de uma explicitação de algo que se realiza, estaria desvelando, ao mesmo tempo, os aspectos subjetivo e objetivo do problemaeducação.

3. A pesquisa gerada pela pergunta pedagógica tem como ponto de partida o senso comum.

3.1. A pergunta pedagógica é posta ao nível do senso comum, mas o próprio fato da sua formulação já aponta para a superação do senso comum. Assim, o sentido da educação é possível com a condição de que a pesquisa proceda a uma análise e superação das contradições de que está povoado o senso comum.

3.1.1. Em primeiro lugar será preciso pôr em evidência as diferentes manifestações do fenômeno educação; nessa etapa, o seu sentido próprio, a sua essência, ainda não pode ser revelada;

3.1.2. No entanto, a partir das diferentes manifestações do fenômeno educação será possível de- tectar o núcleo válido do senso comum (o bom senso); a questão pedagógica poderá ser posta, então, de modo claro e transparente.

3.1.3. A busca cognitiva que caracteriza o inquérito se processa, pois, em dois níveis:

3.1.3.1. O nível fenomênico e o nível da essência: 3.1.3.1.1. O primeiro nível comporta um inventário das diferentes maneiras como os professores percebem a educação em termos do senso comum;

3.1.3.1.2. O segundo nível comporta uma apreensão da essência da educação, o que implica uma superação do senso comum, incorporando, entretanto, em termos elaborados, o seu núcleo válido: o bom senso.

4. Os itens 4.1, 4.2 e 4.3 são algumas ilustrações das diferentes formas de se colocar a questão pedagógica no nível do senso comum. Iniciando a investigação sobre a pergunta pedagógica a partir da relação professor-aluno na instituição é preciso levar em conta o exposto no item 2.3, isto é, o caráter de “serrelações sociais” de que está investido tanto o professor quanto o aluno. Com efeito, o homem é aquele ser natural (indivíduo) que para existir necessita transformar a natureza. Transformando a natureza o homem cria as relações sociais, vale dizer, produz sua própria existência. A essência humana, a sua nota distintiva, aquilo que o diferencia dos demais seres consiste nas relações sociais. Sendo a existência humana um processo contínuo de produção (criativa e reiterativa) das relações sociais, o homem é um ser histórico. É isso o que se quer dizer quando se afirma que a essência do homem é mutável. O modo de produção, determinando o ser do homem, determina, em conseqüência, as demais manifestações humanas. Portanto, determina também o ser da educação. Ao propormos a pergunta pedagógica, vale dizer, ao nos interrogarmos sobre o ser da educação com a qual nos encontramos comprometidos, a investigação daí decorrente não poderá evitar a análise da forma concreta assumida pelo modo de produção na etapa histórica em que se processa a investigação. Com efeito, é essa análise que tornará possível revelar o significado de professor, aluno, instituição, especialidades, profissões, conhecimentos, teoria, métodos etc. E, em última instância, o significado da educação como projeto humano estará na dependência da resposta que se der à seguinte questão: deve a educação concorrer para manter ou para trans- 
formar o vigente modo de produção da existência? Respondida essa questão, será possível compreender em que medida, em quais condições e em que limites poderá a educação desenvolvida na PUC-SP integrar o projeto humano referido.

5. Uma indagação: Até que ponto o ser da educação pode ser separado das entidades em que ela se manifesta fenomenicamente? Isso não significa transformar o ser (da educação) numa espécie de idéia platônica? Ver, a respeito, a afirmação de Heidegger, em 1943: “O ser de fato vem à presença sem o ente”, negada em 1949 pelo mesmo Heidegger: O ser nunca vem à presença sem o ente” e "um ente nunca é sem o ser” (Cf. Bornheim, 1977, p. 133).

Infelizmente, parece que o Grupo de Apoio Didático-Pedagógico parou por aí. Com efeito, não tenho conhecimento de que outros professores tenham atendido ao apelo do professor Joel, elaborando comentários às suas “reflexões sobre educação”. Mas, independentemente disso, Joel prosseguiu, pelos meios de que dispunha, em sua incansável tarefa de animar a vida universitária, buscando aprimorar a qualidade do trabalho educativo. E, dentre suas iniciativas, aquela que teve caráter mais duradouro e grande efeito multiplicador, à vista de sua forma institucionalizada, foi, sem dúvida, a pós-graduação.

Joel Martins tinha uma idéia muito clara do significado próprio da pós-graduação stricto sensu. Essa, diferentemente da graduação, que se destina à formação profissional, volta-se para a formação acadêmica traduzida no preparo de pesquisadores. Nessa condição, diferentemente da graduação e da pós-graduação lato sensu, que têm como elemento definidor o ensino, a pós-graduação stricto sensu tem como elemento definidor a pesquisa. Esta determina o objetivo a ser alcançado, para o qual o ensino concorre como uma mediação destinada a dispor e garantir os requisitos para o desenvolvimento da pesquisa que será a pedra de toque da formação pretendida. Diante disso, Joel adotou na PUC-SP a denominação "Programa de Estudos Pós-Graduados”, em lugar de “Curso de PósGraduação”, que era a forma comumente utilizada nas demais universidades.
Obs.: os itens 6, 7, 8, 9, 9.1 e 9.2 podem ser relacionados com comentários feitos anteriormente.

9.2.1. Como ser histórico, o homem tem a sua essência (as relações sociais) configurada a partir do modo de produção da existência. Assim sendo, o homem sempre propõe os problemas a partir da posição que ocupa no conjunto das relações sociais. Portanto, os pressupostos são inevitáveis. O que se faz necessário, então, é explicitar os pressupostos, revelar as suas bases, submetêlos a uma crítica impiedosa, vale dizer, situá-los no nível concreto-histórico.

A distinção entre "curso" e "programa” reside no fato de que o termo curso se liga diretamente ao ensino e seu centro é um elenco de disciplinas que os alunos devem cursar. Ora, essa é a característica específica tanto da graduação quanto da pós-graduação lato sensu. Em contrapartida, a pós-graduação stricto sensu, além do ensino, envolve, como elemento central, a pesquisa. Daí, a adoção do termo programa para abarcar tanto as atividades de ensino quanto de pesquisa. Assim, um programa de pós-graduação, seja ele de mestrado ou de doutorado ou ambos, tem como centro o programa de pesquisa que o aluno desenvolverá e que deverá resultar na dissertação de mestrado ou tese de doutorado; e, como apoio a essa atividade, ele cursa, também, um elenco de disciplinas disposto em função da área e do tema de sua pesquisa.

Essa distinção foi-se impondo e, uma vez incorporada à história de nossa pós-graduação, acabou por ser também consagrada no texto da nova LDB, a lei $\mathrm{n}^{\circ}$ 9.394, promulgada em 20 de dezembro de 1996. Essa lei reserva o termo programa para a pós-graduação stricto sensu, utilizando o termo curso para a pós-graduação lato sensu, conforme estipulado no artigo 44:

A educação superior abrangerá os seguintes cursos e programas: I - cursos seqüenciais [...]; II - de graduação [...]; III - de pós-graduação, compreendendo programas de mestrado e doutorado, cursos de especialização, aperfeiçoamento e outros, abertos a candidatos diplomados em 
cursos de graduação e que atendam às exigências das instituições de ensino. (grifos meus)

Diante do exposto, entende-se que a proposta de um curso de aperfeiçoamento ou especialização se justifica em conseqüência do avanço do conhecimento decorrente do desenvolvimento da pesquisa na área em questão, cujos resultados afetam o perfil da profissão correspondente. Nesse caso o curso de pósgraduação lato sensu se proporá a garantir a assimilação dos procedimentos ou resultados do avanço da pesquisa, por parte dos profissionais da área em referência, ajustando o seu perfil às mudanças operadas no perfil da sua profissão. Os programas de pós-graduação stricto sensu, por sua vez, se justificam não apenas em razão da necessidade de assimilação dos procedimentos e resultados da pesquisa, mas tendo em vista o próprio avanço do conhecimento, isto é, o desenvolvimento das pesquisas numa área determinada, contribuindo diretamente para essa finalidade (Saviani, 2002, p. 137-138). A contribuição do professor Joel para fixar esse entendimento, possibilitando uma compreensão mais precisa do significado próprio da pós-graduação stricto sensu, foi decisiva.

DERMEVAL SAVIANI, doutor em filosofia da educação pela Pontifícia Universidade Católica de São Paulo (PUC-SP) e livredocente em história da educação pela Universidade Estadual de Campinas (UNICAMP), é professor emérito da UNICAMP e autor, entre outras obras, de Escola e democracia (Campinas: Autores Associados, 2005, 37ª ed.); Pedagogia histórico-crítica (Campinas: Autores Associados, 2005, $9^{\mathrm{a}}$ ed.); e, em colaboração, $O$ legado educacional do século XX no Brasil (Campinas: Autores Associados, 2004). Desenvolve atualmente o projeto "O espaço acadêmico da pedagogia no Brasil: perspectiva histórica e teórica”, com apoio do Conselho Nacional de Desenvolvimento Científico e Tecnológico (CNPq).E-mail: dermevalsaviani@yahoo.com.br

\section{Referências bibliográficas}

BICUDO, Maria Aparecida Viggiani, ESPÓSITO, Vitória Helena Cunha, (2002). Joel Martins: a coragem de ser educador. In: GARCIA, Walter (org.). Educadores brasileiros do século XX. Brasília: Plano, p. 173-200.

BORNHEIM, Gerd Alberto, (1977). Dialética: teoria, práxis. Porto Alegre: Globo; São Paulo: EDUSP.

BRASIL, Ministério da Educação e Cultura, CFE, (1965). Parecer $n^{\circ}$ 977/65. Documenta, no 44, dez. p. 67-86. , (1969). Parecer 77/69. Documenta, $n^{\circ} 98$, fev. p. 128-132.

BRASIL. Lei $n^{\circ}$ 5.540, de 28 de novembro de 1968. Fixa normas de organização e funcionamento do ensino superior e sua articulação com a escola média, e dá outras providências. . Lei $n^{\circ}$ 9.394, de 20 de dezembro de 1996 (Lei de Diretrizes e Bases da Educação Nacional).

BUFFA, Ester, NOSELLA, Paolo, (2001). A educação negada: introdução ao estudo da educação brasileira contemporânea. $3^{\mathrm{a}}$ ed. São Paulo: Cortez.

NAGAMINE, José Massafumi, (1997). Universidade e compromisso social: a experiência da reforma da PUC de São Paulo. São Paulo: EDUC; Campinas: Autores Associados.

SAVIANI, Dermeval, (2002). A pós-graduação em educação no Brasil: pensando o problema da orientação. In: BIANCHETTI, Lucídio, MACHADO, Ana Maria Netto (orgs.). A bússola do escrever: desafios e estratégias na orientação de teses e dissertações. São Paulo: Cortez; Florianópolis: Ed. da UFSC, p. 135-163.

SILVA, Sônia Aparecida Ignácio, (1993). Educação/cultura na memória de profissionais da educação: reflexões sobre experiências na escola pública paulista (1930-50). Tese de doutorado. Pontifícia Universidade Católica de São Paulo. V. II, Anexo, Depoimento I, p. 1-34.

Recebido em março de 2005 Aprovado em maio de 2005 


\section{Resumos/Abstracts}

Dermeval Saviani

O protagonismo do professor Joel Martins na pós-graduação

$\mathrm{O}$ artigo destaca o papel desempenhado pelo professor Joel Martins na implantação, desenvolvimento e consolidação da pós-graduação no Brasil. Para atingir esse objetivo o texto reconstrói a trajetória de vida, estudos e trabalho de Joel Martins; mostra as iniciativas por ele tomadas na criação dos programas de estudos pós-graduados da Pontifícia Universidade Católica de São Paulo (PUC-SP); situa essas iniciativas no âmbito de uma preocupação mais ampla com a questão da qualificação docente e formação de quadros para desenvolver pesquisas na universidade; e conclui enfatizando a importância da contribuição de Joel Martins para a compreensão da especificidade da pósgraduação stricto sensu evidenciada na introdução da terminologia "programas de estudos pós-graduados” em lugar de “cursos” para caracterizá-la. A elaboração do trabalho baseou-se no testemunho do próprio autor e em depoimentos de Joel Martins colhidos por outros pesquisadores, sendo enriquecido por dois documentos inéditos.

Palavras-chave: pós-graduação no Brasil; Joel Martins; educação brasileira

The protagonism of Professor Joel Martins in the field of postgraduate studies
This article highlights the role played by professor Joel Martins in implanting, developing and consolidating postgraduate studies in Brazil. To achieve this goal, the text reconstructs the trajectory of Joel Martins' life, studies and work, pointing out the initiatives he took in the creation of postgraduate programmes at the Pontifícia Universidade Católica de São Paulo (PUC-SP). It situates these initiatives in the context of a wider preoccupation with the question of teacher qualification and the formation of cadres capable of developing research in the university. It concludes by emphasising the importance of the contribution of Joel Martins for an understanding of the specificity of postgraduate studies stricto sensu made evident by the introduction of the terminology "programmes of postgraduate studies" instead of "courses". The work is based on the first hand experience of the author himself and on declarations by Joel Martins collected by other researchers, enriched by two unpublished documents.

Key-words: postgraduate studies in Brazil; Joel Martins; Brazilian

education 